\title{
An Actual Measurement and Analysis on the Heat Insulation Effect of the Building Envelope in Taiyuan South Passenger Depot
} \\ ${ }^{1}$ School of Civil Engineering and Architecture, Hubei University of Technology \\ ${ }^{2}$ Wuhan east lake college \\ a645187499@qq.com, b172335016@qq.com, '115642800@qq.com
}

\begin{abstract}
Keywords:building envelope; double-skin façade; heat insulation effect; building energy conservation.

Abstract. TBuilding envelope has an insulating effect. This paper takes the building envelope in Taiyuan South Passenger Depot as an object of study, and this object is a double-skin facade. By collecting data on the surface temperature and air interlayer temperature of the inner and outer skin components based on a practical measurement before data reduction and analysis, the paper researches the impact of double-skin facade on the thermal performance of building envelope in practical engineering applications, to verify the heat insulation effect of the double-skin facades designed based on passive energy-saving, aimed at providing references for the research and application of building energy efficiency.
\end{abstract}

\section{Introduction}

Many countries and regions at home and abroad have carried out correlational studies on the thermal performance and climate adaptability design of double curtain building[1], mostly on double glass curtain wall, while rarely on the double composite curtain wall in which glass is combined with stone. By taking the double composite curtain wall in Taiyuan South Passenger Depot for example, this paper makes a practical measurement to analyze the heat insulation effect of the double-skin facade of this building, to provide more references for the energy conservation design of buildings.

\section{An Introduction to the Enclosure System in Taiyuan South Passenger Depot}

The enclosure system in Taiyuan South Passenger Depot is a novel curtain wall made of double glass and stone. This curtain wall is composed of two layers of stone and two layers of glass. In the composite curtain wall, the stone curtain wall and glass curtain wall share the same steel joist, and the surface of the joist is galvanized by dipping. The aluminum profile is $2.5 \mathrm{~mm}$ thick; for the outer curtain wall, 6+12A+6 tempered LOW-E hollow glass is adopted, for the inner curtain wall, 6-mm-thick single tempered glass is adopted, and for the stone curtain wall, 25-mm-thick buffed granite, native to Jinan, is adopted; besides, between the surfaces of the double-layer composite curtain wall there is a 600 -mm-thick air interlayer(see Fig.1).

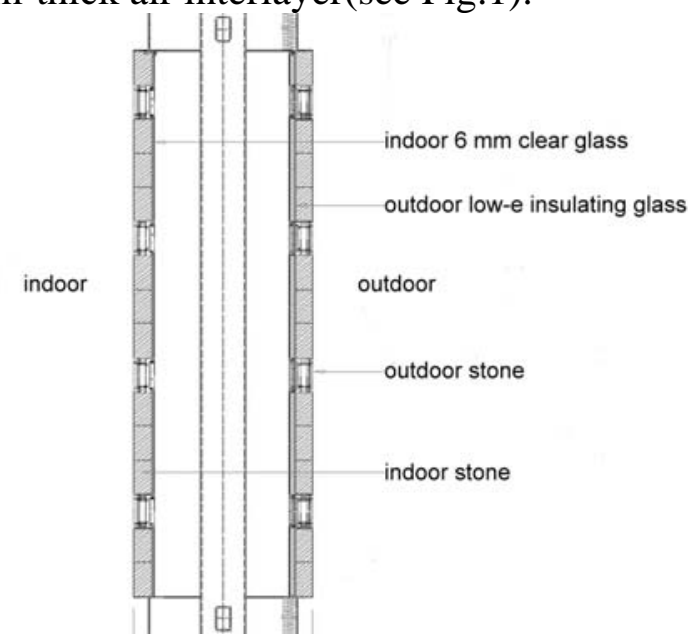

Fig.1.a structural map of the composite curtain wall in Taiyuan South Passenger Depot 


\section{A Brief Introduction to the Actual Measurement}

Research Center for Green Architecture of Hubei University of Technology conducted a field measurement on Taiyuan South Passenger Depot from January 6 to 8, 2015. The measurement was made from 0: 00 to 24: 00 , and the indoor supply air temperature was $39.2^{\circ} \mathrm{C}$ all day long during the measurement. Taiyuan City was in the coldest days of winter when the actual measurement was conducted. The wind velocity and temperature were low, the weather was fine, but clouds came now and then, and the solar radiation was weak. It was a typical cold climate. This paper makes a selective analysis on the various data collected on January 7.

Four actual measuring points were set up this time. The position and content of each measuring point, as well as the instruments used, are as shown in Tab.1. To be specific, the outside surface temperature of the granite in the outer curtain wall (1), the outside surface temperature of the hollow glass in the outer curtain wall (2), the inner surface temperature of the hollow glass in the outer curtain wall (3), the temperature of the air interlayer (4), the outside surface temperature of the single glass in the inner curtain wall (5), the inner surface temperature of the single glass in the inner curtain wall (6), and the inner surface temperature of the granite in the inner curtain wall (7) (see Fig.2) were measured at each measuring point at the same height, so the name of measuring point $E$ at each point is E1, E2, E3, E4, E5, E6 and E7 respectively, and this method is also applied to the rest three actual measuring points.

Tab.1.measurement contents and instruments used

\begin{tabular}{|c|c|c|c|c|}
\hline $\begin{array}{c}\text { Measuri } \\
\text { ng Point }\end{array}$ & $\begin{array}{c}\text { Measuring Point } \\
\text { Position }\end{array}$ & $\begin{array}{c}\text { Measuring Point } \\
\text { Content }\end{array}$ & $\begin{array}{c}\text { Instruments } \\
\text { Used }\end{array}$ & $\begin{array}{c}\text { Sampling } \\
\text { Frequency }\end{array}$ \\
\hline $\mathrm{E}$ & $\begin{array}{c}\text { The composite curtain } \\
\text { wall in the east } \\
\text { entrance hall }\end{array}$ & Temperature & $\begin{array}{c}\text { Ibutton } \\
\text { acquisition } \\
\text { instrument }\end{array}$ & 10min \\
\hline $\mathrm{W}$ & $\begin{array}{c}\text { The composite curtain } \\
\text { wall in the west } \\
\text { entrance hall }\end{array}$ & Temperature & $\begin{array}{c}\text { Ibutton } \\
\text { acquisition } \\
\text { instrument }\end{array}$ & 10min \\
\hline S & $\begin{array}{c}\text { The south composite } \\
\text { curtain wall }\end{array}$ & Temperature & $\begin{array}{c}\text { Ibutton } \\
\text { acquisition } \\
\text { instrument }\end{array}$ & 10min \\
\hline $\mathrm{N}$ & $\begin{array}{c}\text { The north composite } \\
\text { curtain wall }\end{array}$ & Temperature & $\begin{array}{c}\text { Ibutton } \\
\text { acquisition } \\
\text { instrument }\end{array}$ & 10min \\
\hline
\end{tabular}
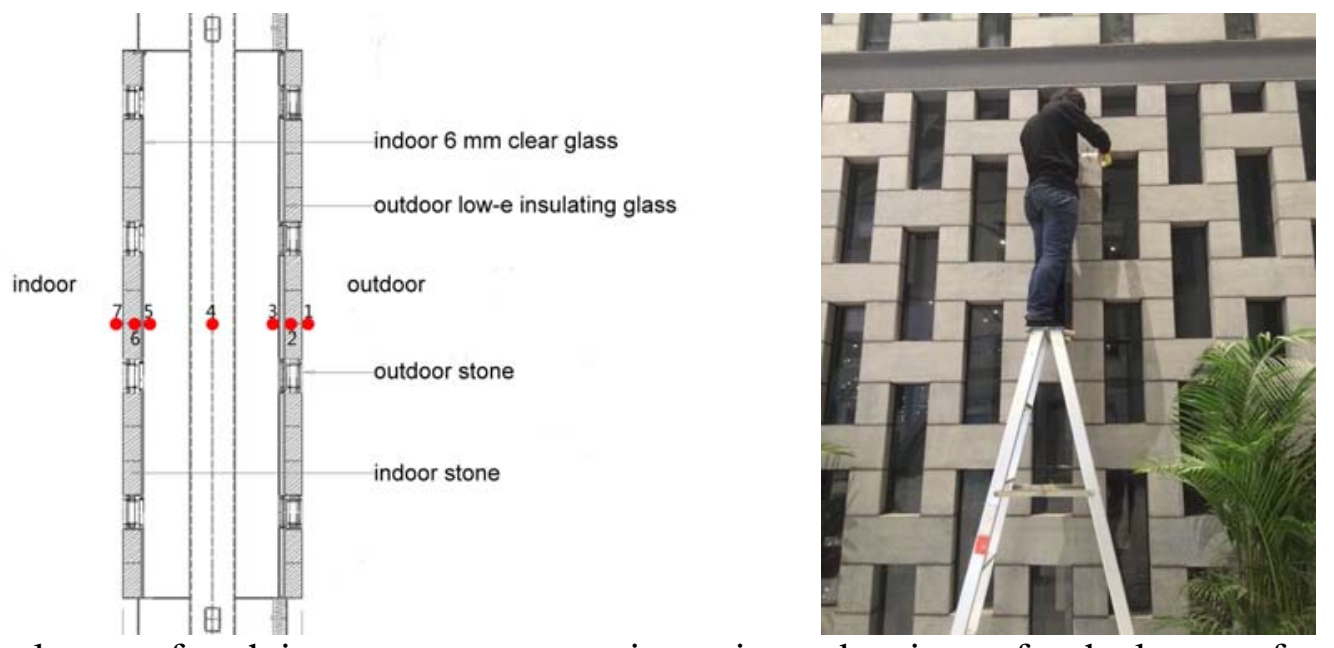

Fig.2.the layout of each instrument at measuring point and a picture for the layout of some instruments 


\section{The Measured Result and an Analysis on it}

An analysis on the outside surface temperature of the stone in the east, west, north and south

Fig.3 shows the change in the outside surface temperature of the stone in the east, west, north and south of Taiyuan South Passenger Depot. A comparison suggests that owing to the difference in orientation, there are different temperature differences and fluctuation ranges, and the temperature at measuring point S1 is, by and large, always at the peak, while that at measuring point N1 is, by and large, at the bottom. This has something to do with the externalities of the measuring points, that is, with the geographic position, solar radiation, climatic variation, air motion and heat source, etc. [2], mainly because solar radiation can heat building surface. Solar radiation effect is, on the one hand, the major cause for excessively high indoor temperature in summer, and on the other hand, a natural source of energy for the improvement of indoor temperature in winter.

As is shown in Fig.3, the maximum temperature at point $\mathrm{E} 1$ is $4^{\circ} \mathrm{C}$, and the minimum temperature is $-2^{\circ} \mathrm{C}$, where temperature variance is inconspicuous. This is because measuring point E1 is located at the surface of the outer stonewall in the east entrance hall, where there is a lack of direct solar radiation throughout the day; the maximum temperature at point $\mathrm{W} 1$ is $25^{\circ} \mathrm{C}$, and the minimum temperature is $-1.5^{\circ} \mathrm{C}$, where the temperature variance is $26.5^{\circ} \mathrm{C}$, and that the temperature becomes gradually higher than that at measuring point $\mathrm{S} 1$ at 14 : 30, because sunlight fully hits the exterior wall in the west at that time, leading to an increase in the surface temperature of the exterior wall; the temperature at measuring point S1 is always maintained at a high level, and that it reaches its maximum $29.5^{\circ} \mathrm{C}$ at 12 : 30 , primarily due to the effect of solar radiation; the temperature at measuring point $\mathrm{N} 1$ is, by and large, at the bottom, and rises rapidly at 14: 00 owing to the effect of solar radiation; the temperature at measuring point $\mathrm{W} 1$ and $\mathrm{N} 1$ falls rapidly after 18: 00, possibly because the northwest wind sprang up in the night, which came against the outer wall surface and led to an obvious decrease in the temperature.

This shows that external environment isn't changeless. Therefore, when building envelope construction is designed, for the same building, different envelope systems can be adopted in different directions according to its geographical location and external environments[3].

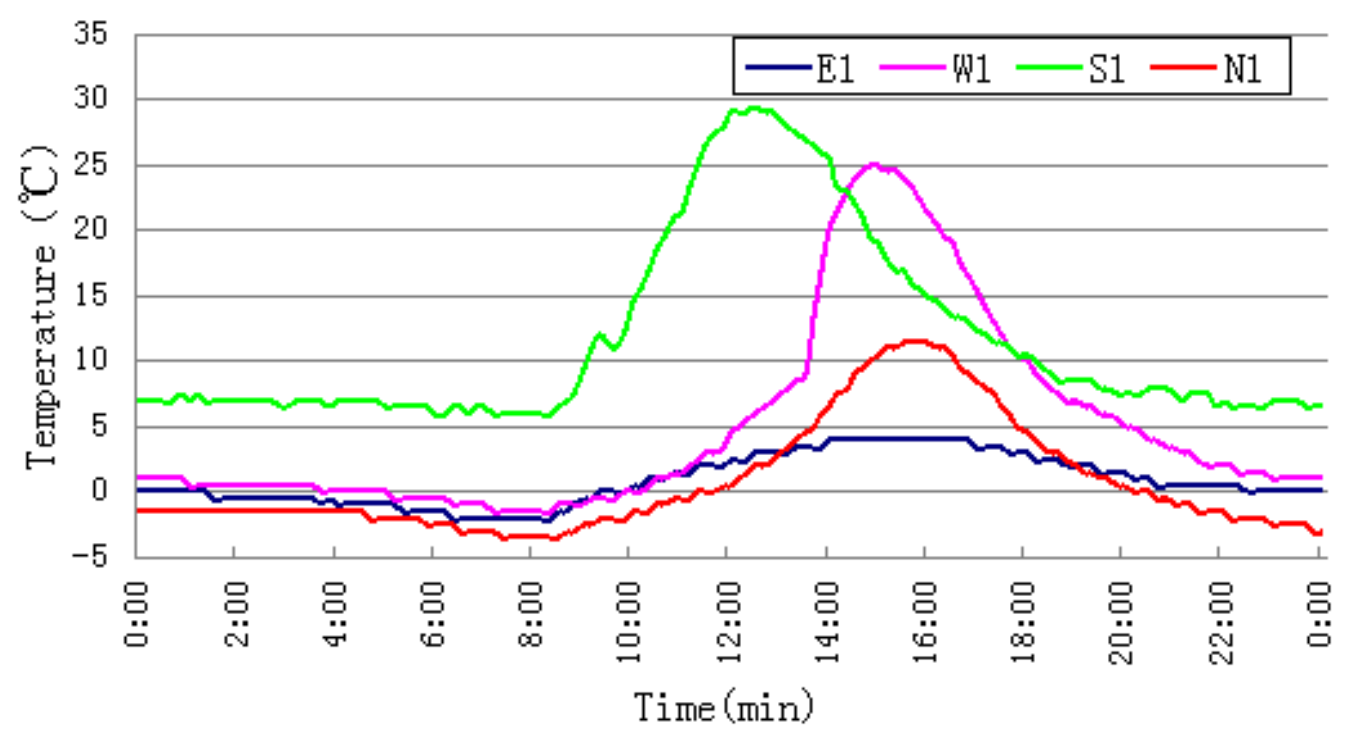

Fig.3.the variation diagram of the temperature at measuring point E1, W1, S1 and N1 on Jan. 1, 2015 An analysis on the composite curtain wall temperature

Fig.4 and Fig.5 respectively reflect the change in the instrument temperature at the locations in measuring point $\mathrm{E}$ and $\mathrm{W}$ in Taiyuan South Passenger Depot. A comparison in the instrument temperature at different locations in the same measuring point shows that except the lower outside surface temperature of the hollow glass in the exterior wall than that of the stone in the exterior wall, the closer the instruments are to the indoor space, the higher the measured temperature is, suggesting that composite curtain wall has a very good insulation stability[4]. 


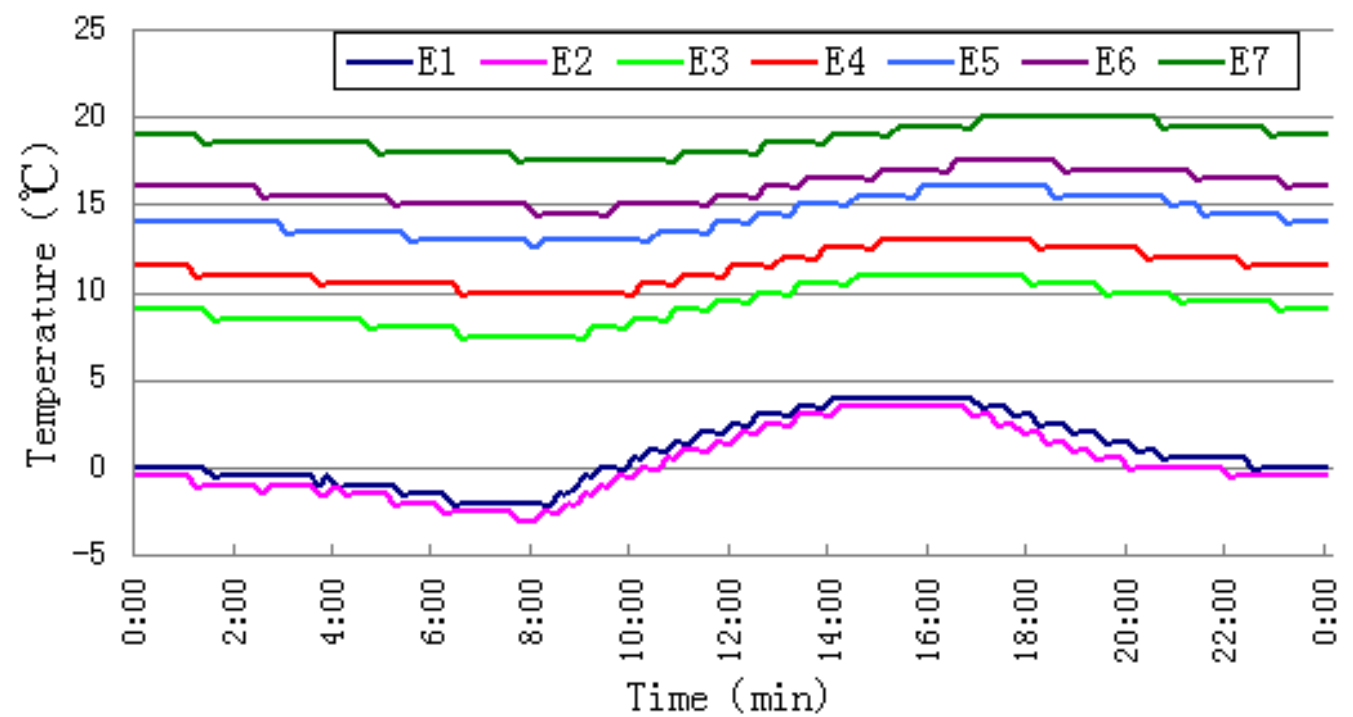

Fig.4.the variation diagram of the instrument temperature at each location in measuring point $E$ on Jan. 1, 2015

As is shown in Fig.4, the temperature at measuring point E7 is always at the peak, and the maximum temperature is $20^{\circ} \mathrm{C}$. The temperature at measuring point $\mathrm{E} 2$ is always at the bottom, and the maximum temperature is $3.5^{\circ} \mathrm{C}$, with the temperature difference reaching $16.5^{\circ} \mathrm{C}$, suggesting that this composite curtain wall has a good heat insulation effect. Both measuring point E1 and E2 are located at the outside surface of the outer curtain wall, but there is some difference in their temperature: the maximum temperature at point $\mathrm{E} 1$ is $4^{\circ} \mathrm{C}$, while the minimum temperature is $-2^{\circ} \mathrm{C}$; the maximum temperature at point $\mathrm{E} 2$ is $3.5^{\circ} \mathrm{C}$, while the minimum temperature is $-3^{\circ} \mathrm{C}$. This has something to do with the materials' thermal conductivity. Measuring point E1 is located at the surface of the granite, and granite's thermal conductivity is $25.49 \mathrm{~W} /\left(\mathrm{m}^{2} \cdot \mathrm{K}\right)$, while measuring point E2 is located at the surface of the hollow glass, and hollow glass' thermal conductivity is $10.69 \mathrm{~W} /\left(\mathrm{m}^{2}\right.$ $\bullet \mathrm{K})[5]$. When the external ambient temperature is constant, the heat absorbed by granite is higher than that absorbed by hollow glass, so it's certain that the temperature at measuring point E1 is a little higher.

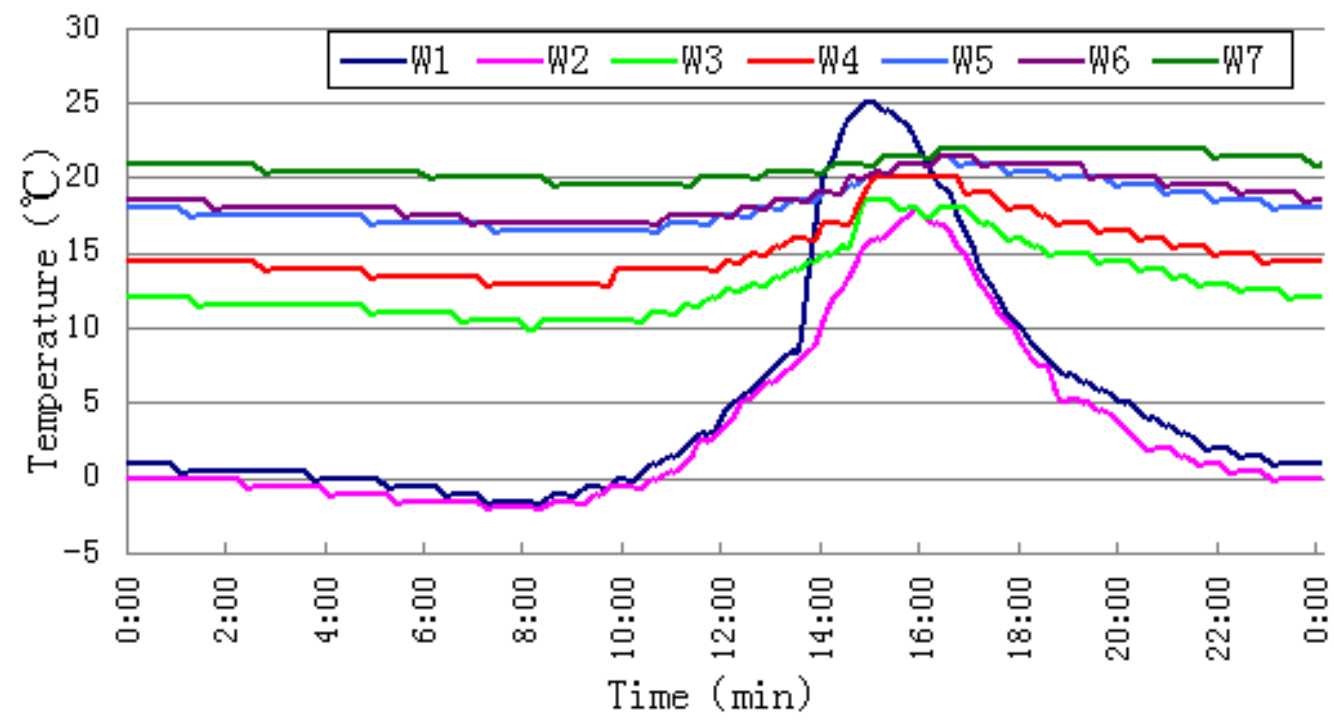

Fig.5.the variation diagram of the instrument temperature at each location in measuring point $\mathrm{W}$ on Jan. 1, 2015

Fig. 5 shows that the temperature at measuring point $\mathrm{W} 7$ is basically maintained at the maximum value, and the highest temperature is $22{ }^{\circ} \mathrm{C}$; the temperature at measuring point $\mathrm{W} 2$ is always at the peak, and the highest temperature is $18{ }^{\circ} \mathrm{C}$. The temperature at measuring point $\mathrm{W} 1$ and $\mathrm{W} 2$ begins to 
rise drastically after 14:00. The temperature at measuring point $\mathrm{W} 1$ even exceeds that at measuring point W7 at 14:30, and that the highest temperature reaches $25^{\circ} \mathrm{C}$, while the maximum temperature at measuring point $\mathrm{W} 2$ also reaches $18^{\circ} \mathrm{C}$. This is due to the location of measuring point $\mathrm{W} 1$ and $\mathrm{W} 2$ at the surface of the west outer curtain wall. It receives direct solar radiation and absorbs most of the solar radiation after 14: 00 , so the temperature shows up a wide fluctuation. Moreover, due to the difference of heat storage coefficient, the temperature at measuring point $\mathrm{W} 1$ is a bit higher [6]. The temperature at measuring point $\mathrm{W} 3, \mathrm{~W} 4, \mathrm{~W} 5, \mathrm{~W} 6$ and $\mathrm{W} 7$ is relatively stable, and this partly shows that this composite curtain wall has a good heat insulation effect.

Comfortable indoor temperature in winter is between 18 and $20^{\circ} \mathrm{C}$. So here, an analysis is carried out on the duration of the internal surface temperature of the stone in the interior curtain wall in the east and west with $18^{\circ} \mathrm{C}$ as a demarcation line (see Fig.6). As is illustrated in Fig.6, the duration is 21 hours as the temperature at measuring point E7 reaches $18^{\circ} \mathrm{C}$, and the duration is 24 hours as the temperature at measuring point $\mathrm{W} 7$ reaches $18^{\circ} \mathrm{C}$. The average duration rate of both is up to $93.75 \%$. This partly suggests that this composite curtain wall has a low heat conductivity coefficient, that is, it has a good thermal insulation property. This measured result indicates that as a passive energy conservation design instrumentality, this sort of composite curtain wall[7] can play a positive role in maintaining indoor temperature and lightening air conditioning's heating load in winter.

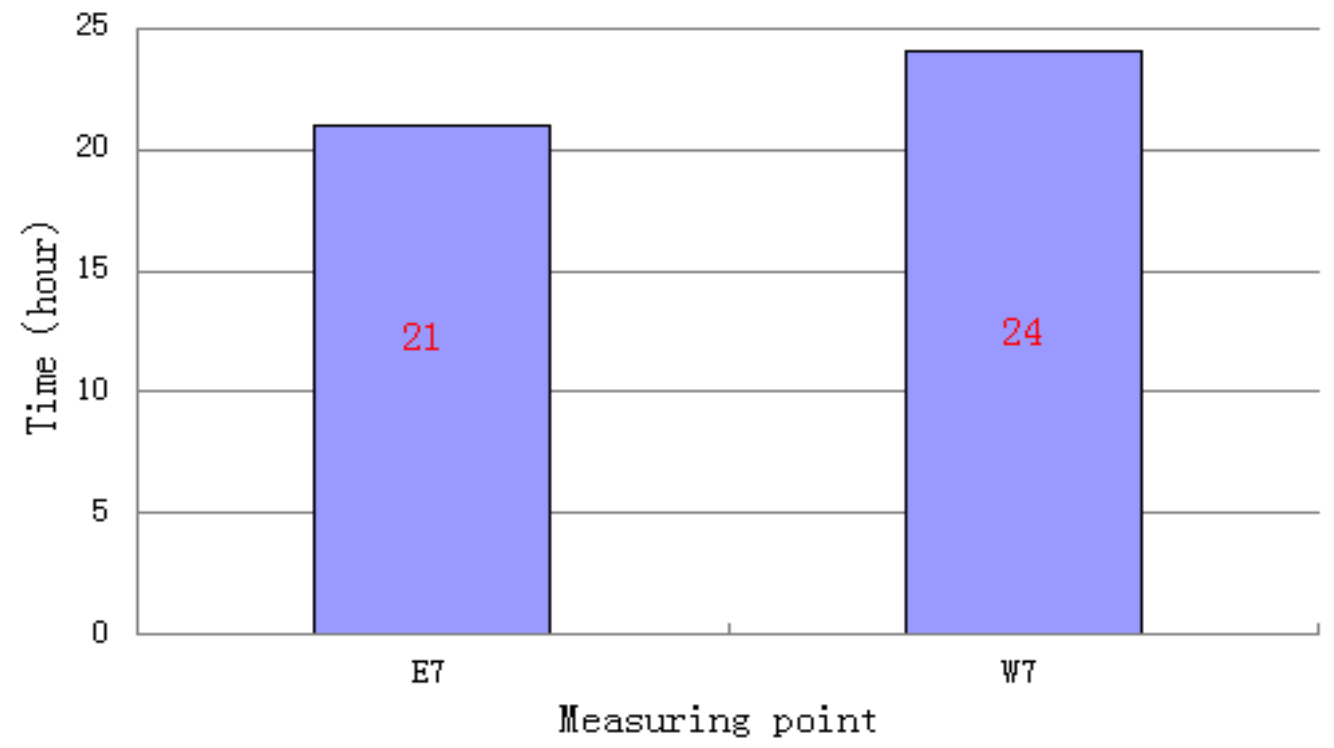

Fig.6.a comparison in the duration of the temperature at measuring point E7 and W7 on Jan. 1, 2015

\section{Conclusions}

The following conclusions can be drawn according to the measured data as well as an analysis and comparison on it:

1) External environment isn't changeless. When building envelope construction is designed, for the same building, different envelope systems can be adopted in different directions according to its geographical location and external environments[8].

2) The temperature of composite curtain wall doesn't decrease progressively as we think. During the measurement, the outside surface temperature of the hollow glass in the outer curtain wall was always lower than that of the stone, suggesting that as there was a difference in materials' thermal conductivity, there would be a difference in materials' surface temperature.

3) Composite curtain wall has a good heat insulation effect in winter. Calculation shows that the average heat transfer coefficient of the outer curtain wall of the whole building in Taiyuan South Passenger Depot is only $0.39 \mathrm{~W} /\left(\mathrm{m}^{2} \cdot \mathrm{K}\right)$, far below $0.60 \mathrm{~W} /\left(\mathrm{m}^{2} \cdot \mathrm{K}\right)$, the existing energy-saving standard. Besides, between the double-layer composite curtain wall surfaces there is a 600 -mm-thick air layer, which helps greatly enhance the thermal inertia of the building skin, ensuring the stability of indoor temperature, and helps greatly reduce the operational energy consumption of the station in frigid winter. 


\section{Acknowledgements}

A Study on the Technology Guide of Constructing Low-carbon City in Wuhan based on the Climatic Characteristics(D20141402)

A Study on the Standard System Construction and Development Mode in the Low-carbon Industrial Park in Wuhan(WHJT-CZH—2014-1141)

\section{References}

[1] Wu Linghong, Ye Dafa \& Zhou Zhong et al. The Thermal Insulation Performance and Air-conditioning Energy Consumption of Office Building Envelope[J]. Building Energy Efficiency, 2007 (2): 18-21.

[2] Lin Borong, Li Xiaofeng \& Zhu Yingxin. Experimental Studies on Building Exterior Microclimate in Solar Radiation- Building Exterior Temperature Distribution and Airflow Characteristics[J]. Acta Energiae Solaris Sinica, 2001 (3): 327-332.

[3] Xu Zilong, Di Yuhui \& Liu Ying. The Current Research and Design Situation of indoor Thermal Environment in Large-scale Public Buildings[J]. Contamination Control \& Air-Conditioning Technology, 2013 (2): 68-73.

[4] Wang Hongshu. A Research on the Heat Insulation of Building External Envelope[J]. Science \& Technology Information, 2013 (2): 68-73.

[5] GB 50176-93. Thermal Design Code for Civil Building[S].

[6] Huang Chen, Li Meiling \& Zou Zhijun et al. A Field Measurement of Indoor Thermal Environment in Large-space Buildings and Energy Consumption Analysis [J]. Journal of HV\&AC, 2002 (2): 5-7.

[7] Luo Jing. A Research on Energy Saving Reconstruction of Existing Buildings in Cold Regions and Assessment of Energy Consumption[D]. Xi'an: Xi'an University of Technology, 2008.

[8] Zhou Siyu. The Impact of the Building Envelope Energy Saving Technologies on Building Energy Consumption in Different Climate Areas[D]. Tianjin: Tianjin University, 2012. 